\title{
Porosity change model for watered super absorbent polymer-treated soil
}

\author{
Yu Guo Han · Pei Ling Yang • Yuan Pei Luo • \\ Shu Mei Ren $\cdot$ Li Xia Zhang $\cdot$ Lei Xu
}

Received: 25 July 2009/Accepted: 29 December 2009/Published online: 29 January 2010

(C) Springer-Verlag 2010

\begin{abstract}
Drought is a great concern in agricultural production, because it restricts normal plant growth, brings about enormous economic loss and deteriorates ecological environment. Proper use of super absorbent polymers (SAP) is helpful in the agricultural and horticultural industry in arid and semi-arid areas, because SAP can ease the burden of water shortage. Because porosity is one of the most important soil physical properties, it is a priority to study SAP to quantitatively express the swelling of watered SAPtreated soil. This study was aimed to evaluate the bulk density curve of watered SAP-treated soil and to construct and test the model for porosity change of watered SAPtreated soil. The results showed that the application of SAP can reduce soil bulk density, improve soil permeability and cause soil swelling. In addition, using three factors, i.e.,
\end{abstract}

Y. G. Han · P. L. Yang $(\varangle) \cdot$ S. M. Ren

College of Hydraulic and Civil Engineering,

China Agricultural University, 17 Qinghua Donglu,

Handian District, P. O. Box 57, 100083 Beijing,

People's Republic of China

e-mail: cau.ply@gmail.com

Y. G. Han

State Key Laboratory of Urban and Regional Ecology, Research Center for Eco-Environmental Sciences, Chinese Academy of

Sciences, 100085 Beijing, People's Republic of China

Y. P. Luo

The Chinese Academy of Agricultural Sciences,

100081 Beijing, People's Republic of China

\section{X. Zhang}

Beijing Lecome Intellectual Property Agency Co., Ltd., 100098 Beijing, People's Republic of China

L. Xu

China Irrigation and Drainage Development Center,

100054 Beijing, People's Republic of China water content, change in swelling ratio and SAP application rate, the paper constructed a model for porosity change of watered SAP-treated soil, which is $\left\{\ln \left[\left(P_{\mathrm{m}}-P\right)\left(P_{\mathrm{m}}-\right.\right.\right.$ $\left.P_{0}\right)^{-1}$ ] $\beta P_{0} \theta=-\eta_{0} c \theta-\eta_{0} a$. This is a generic model. Two soil samples, namely, loam and sandy loam, were used to calculate the parameters and test the model. The results of the model were satisfying, thus this model is reliable.

Keywords Super absorbent polymers - Soil porosity · Porosity change model $\cdot$ Soil swelling ratio

\section{Introduction}

Since chemicals were applied in agriculture, researches on the technology of chemical-saving water have been drawing extensive attention. Super absorbent polymers (SAP) are one of the maturely developed chemical water-saving agents. In the 1960s, Gugliemelli et al. (1979), a member of the Northern Regional Research Center of the US Department (NRRC), first developed a kind of SAP composed of starch-polyacrylonitrile graft co-polymer and applied it to agricultural production of corn and soybean as well as seedling transplanting. It was found that SAP contributes to water saving and yield enhancement (Fanta et al. 1971). Grain Processing co. industrialized its manufacture as early as 1974 (Nimah et al. 1983; Hemyari and Nofiiger 1981). SAP is used in many areas such as pharmaceuticals, food packaging (Matsubara and Toa 1990), paper production ( $\mathrm{Li}$ et al. 2004), the agricultural and horticultural industry (Wang et al. 2000a, b), oil drilling (Wang et al. 1998), etc.

Drought is a great concern in agricultural production. Compared with other adverse environmental causes, drought, whether permanent or temporary, is much more harmful to plant. It restricts normal plant growth, brings 
about enormous economic loss and deteriorates ecological environment. Proper use of SAP has great significance in the agricultural and horticultural industry in arid and semiarid areas, because it can ease the burden of water shortage. Current studies on SAP mainly focus on the development of its new material and new product (Liu and Rempel 1997; David and De 1994; Achwal 1997) and its own chemical properties (Janardan 1998; Woodhouse and Johnson 1991; Yang et al. 2003) as well as its field application (Swietlik 1989; Han et al. 2005), while few studies relate to the properties of SAP-treated substance (Liu et al. 2005). This paper studied the change of physical properties of SAPtreated soil. After SAP has absorbed water, its capacity of absorbing and desorbing water closely relates to its volume change. Since porosity is one of the most important soil physical properties, it is a priority to study SAP to quantitatively express the swelling of watered SAP-treated soil. The study is a theoretical basis for determining whether SAP can be used properly and effectively.

The first objective of this study was to evaluate the bulk density curve of watered SAP-treated soil, and the second was to construct and test a model for porosity change of watered SAP-treated soil.

\section{Materials and methods}

\section{Materials}

The experimental site of Power and Water Supply Center, located in Daxing District of Beijing and the experimental area of China Agricultural University were used for this study. The soil samples were taken from the layer $20-60 \mathrm{~cm}$, with $\mathrm{pH}$ of 7.0, classified as sandy loam and loam, respectively.

The particle size of soil samples were analyzed and classified according to soil taxonomy developed by United States (Table 1).

Acrylate sodium co-polymers (ASC) used in this experiment is "Kehan 98" produced by Hebei Kehan Resin Ltd. They are white particles with diameter less than $0.02 \mathrm{~mm}$.

PVC cylinders, $250 \mathrm{~mm}$ in outer diameter, $239-240 \mathrm{~mm}$ in inner diameter and $80 \mathrm{~mm}$ in height were used (see Fig. 1).

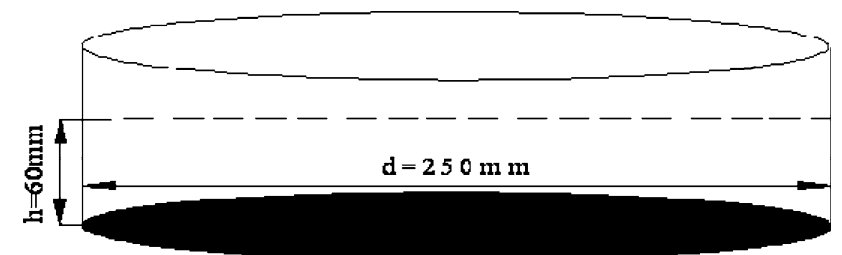

Fig. 1 Cylinder

Table 2 Experimental design

\begin{tabular}{llllllll}
\hline Soil sample & $\begin{array}{l}\text { SAP application } \\
\text { rate (SAP:dry } \\
\text { soil weight ratio) }\end{array}$ & & Water content & & & \\
\hline Sandy loam & $1: 5,000$ & 0.10 & 0.15 & 0.20 & 0.25 & 0.30 & 0.35 \\
& $1: 2,000$ & & & & & & \\
& $1: 1,000$ & & & & & & \\
& $1: 500$ & & & & & & \\
Loam & $1: 5,000$ & 0.10 & 0.15 & 0.20 & 0.25 & 0.30 & 0.35 \\
& $1: 2,000$ & & & & & & \\
& $1: 1,000$ & & & & & & \\
& $1: 500$ & & & & & & \\
\end{tabular}

Methods

The experiment was conducted in Soil Physics Laboratory of China Agricultural University in December 2008.

SAP was mixed with air-dried or oven-dried soil samples in SAP:dry soil weight ratios of 1:5,000, 1:2,000, 1:1,000 and 1:500, respectively.

Water content $\theta$ began at 0.10 and increased at the interval of 0.05 , until it reached 0.35 . The detail of the experimental is designed as shown in Table 2.

Experimental steps

The SAP-loam mixture and the SAP-sand mixture at different SAP:soil ratios were filled in separate cylinders, and were compacted until the bulk density of the mixture in each cylinder was equal to that of the corresponding original soil. The height of SAP-soil mixture in cylinders was $40 \mathrm{~mm}$. The amount of water to be added into each

Table 1 Soil physical properties

\begin{tabular}{llllr}
\hline Soil sample & \multicolumn{2}{l}{ Particle content $(\%)$} & Soil texture & Bulk density \\
\cline { 2 - 4 } & Clay $(<2 \mu \mathrm{m})$ & Silt $(2-50 \mu \mathrm{m})$ & Sand $(50-2,000 \mu \mathrm{m})$ & Sandy loam \\
\hline $\begin{array}{c}\text { Experimental site of Power } \\
\text { and Water Supply Center }\end{array}$ & 7.96 & 39.47 & 52.57 & Loam \\
$\begin{array}{c}\text { Experimental area of China } \\
\text { Agricultural University }\end{array}$ & 9.95 & 46.74 & 43.31 & 1.55 \\
\hline
\end{tabular}


cylinder was determined according to different water contents as shown in Table 2. Water was poured into the cylinders evenly until the water content in each cylinder reached the level as required in Table 2. Then the cylinders were covered with cling wrap for preventing the evaporation of water; $24 \mathrm{~h}$ later, the bulk density of SAP-soil mixture was measured by cutting ring sampling method. Porosity was calculated according to the measured bulk density; each treatment has three replications.

\section{Results}

Bulk density measurement

The height of the SAP-soil mixture in cylinders was too low, so the experiment employed small-sized cutting ring, $52.0 \mathrm{~mm}$ in diameter and $10.0 \mathrm{~mm}$ in height, to measure the bulk density (refers to dry bulk density in this paper) of the SAP-soil mixture. To ensure the accuracy, the values measured with small cutting ring were compared with those measured with big-sized cutting ring, $50.0 \mathrm{~mm}$ in diameter and $50.9 \mathrm{~mm}$ in height. The result is shown in Table 3.

Table 3 shows that the values measured with the two different methods, respectively, are highly consistent. The largest deviation between the value measured with bigsized cutting ring and that measured with small-sized cutting ring is 0.013 , the smallest 0.002 , and the average deviation is 0.0078 . Therefore, the values measured with small-sized cutting ring are as reliable as those measured with big-sized cutting ring.

\section{Soil bulk density}

Soil bulk density is an important indicator of soil physicochemical properties, reflecting the tightness of the pore space in soil. Thus, the experiment studied the bulk density of SAP-treated soil in different SAP:soil ratios so as to further study the porosity. The extent of the swelling of SAP varied with water content, so the bulk density of SAPtreated soil also varied with water content (see Fig. 2).

Figure 2 shows that bulk density was reduced after the soil was treated with SAP, and meanwhile, in each figure, bulk density declined as water content increased. The decline in bulk density indicates the increase in soil porosity. Therefore, the application of SAP can reduce soil bulk density, improve soil permeability and cause soil swelling.

Model for soil porosity change

As mentioned before, after having absorbed water, SAP's capacity of absorbing and desorbing water closely relates to its volume change. Since porosity is one of the most important soil physical properties, it is a priority to study SAP in order to quantitatively express the swelling of watered SAP-treated soil.

\section{Hypotheses for the model}

To quantitatively analyze the swelling of watered SAPtreated soil, the following hypotheses were proposed:

1. SAP was mixed with two kinds of dried soil samples thoroughly, respectively. That is to say, the SAP-soil mixture per unit volume (or mass) contained the same amount of SAP; and SAP particles were small enough and were distributed evenly enough to make the volume change of SAP-treated soil homogeneous and isotropic;

2. the impact of applied SAP itself on soil bulk density was ignored. Therefore, in the following analysis, all the volume changes of SAP-treated soil were caused by SAP's performance of absorbing water;

3. after SAP-treated soil had absorbed water, its volume would change instantaneously. That is to say, volume change was just a function of water content, having nothing to do with time; and

4. at room temperature, the effect of temperature on experiment was ignored, so the volume change caused by temperature change was not taken into account.

The diameter of SAP particle is less than $0.02 \mathrm{~mm}$, similar to that of soil particle, so they can be mixed evenly and isotropically by a mixer. In this experiment, the change of soil bulk density caused by the mixing of SAP and soil was only $0.02-0.2 \%$, so this change was ignored; SPA completed absorbing water and expanded to a maximum

Table 3 Bulk density measured with different-sized cutting ring

\begin{tabular}{|c|c|c|c|c|c|c|c|c|c|}
\hline Given bulk density $\left(\mathrm{g} \mathrm{cm}^{-3}\right)$ & 1.45 & & & 1.50 & & & 1.55 & & \\
\hline Big-sized cutting ring & 1.446 & 1.454 & 1.449 & 1.505 & 1.501 & 1.510 & 1.545 & 1.554 & 1.548 \\
\hline Small-sized cutting ring & 1.443 & 1.441 & 1.447 & 1.492 & 1.509 & 1.502 & 1.540 & 1.552 & 1.542 \\
\hline Deviation & 0.003 & 0.013 & 0.002 & 0.013 & 0.008 & 0.008 & 0.005 & 0.002 & 0.006 \\
\hline Average deviation & 0.0078 & & & & & & & & \\
\hline
\end{tabular}


Fig. 2 Bulk density of SAPtreated soil versus water content $($ SAP:soil = 1:5,000, 1:2,000, $1: 1,000,1: 500$ )
$1: 5000$

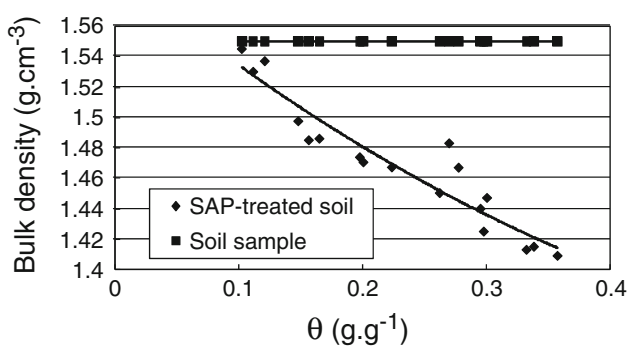

$1: 1000$

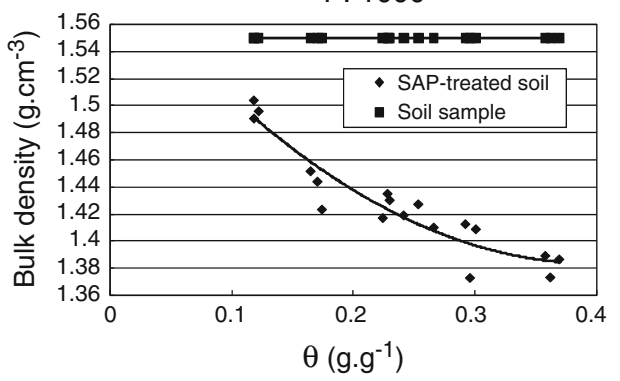

$1: 2000$

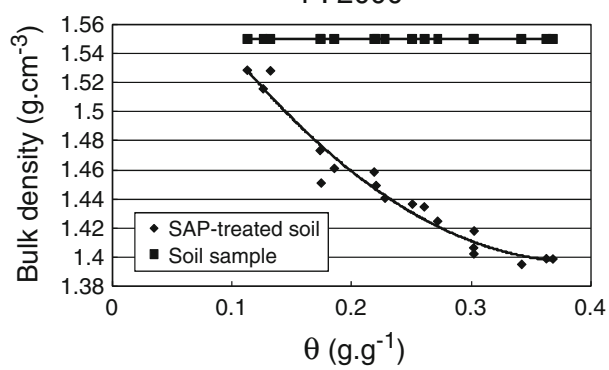

$1: 500$

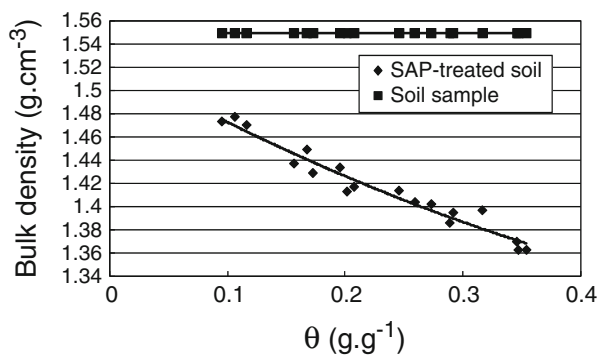

extent in 3-5 min, this duration being so short that it was negligible for the whole experiment, so the change of soil bulk density during this duration was ignored; the temperature in the laboratory is constant, and the properties of SAP is stable below $100^{\circ} \mathrm{C}$ (Janardan 1998), so the change of volume caused by the temperature was ignored. Thus, the above hypotheses can be considered reasonable for the purpose of this study.

\section{Construction of the model}

Soil is generally considered as a continuous medium, so specific volume $P\left(\mathrm{~cm}^{3} \mathrm{~g}^{-1}\right)$, i.e., the volume occupied by a unit of mass of soil was used to indicate soil volume in this paper. After having absorbed water, SAP-treated soil's volume changed significantly, that is, specific volume $P$ is a function of soil mass water content $\theta\left(\mathrm{g} \mathrm{g}^{-1}\right)$.

Under the above hypotheses, the change in specific volume $P$ was mainly affected by the following three factors:

1. Water content It is the basic condition for the volume change of SAP-treated soil. For air-dried or oven-dried soil, the change in $P$, i.e., $\Delta P$, at a certain water content is a function of $\eta(a+b \theta)$, where $\eta$ is the swelling ratio, indicating the ratio of $\Delta P$ to the filled status of soil pores by water $(a+b \theta) ; \eta, a$ and $b$ are all dimensionless constants.

2. Change of swelling ratio The past studies show that volume change varies with water content, but continually watered SAP-treated soil will not keep swelling, instead, it stops when swelling ratio has reached a maximum. This process can be expressed as $\eta=\eta_{0}\left(P_{\mathrm{m}}-P\right)$, where $\eta_{0}$ is a dimensionless apparent swelling ratio, and $P_{\mathrm{m}}$ is the specific volume at the maximum swelling ratio.

3. SAP application rate According to the above hypotheses, after SAP-treated soil has absorbed water, its volume change is caused only by SAP's performance of absorbing water. Obviously, the volume change at a particular water content depends on SAP application rate. Let $W$ be SAP application rate, i.e., the weight of applied SAP per unit mass of soil, then $W=\beta P_{0}$, where $\beta$ is the weight of applied SAP per unit volume of soil $\left(\mathrm{g} \mathrm{cm}^{-3}\right)$; and $P_{0}$ is the specific volume of airdried or oven-dried soil.

By taking above three factors together into account, the numerical model for specific volume change of the soil applied with a certain amount of SAP at a certain water content is constructed as:

$\frac{\mathrm{d} P}{\mathrm{~d} \theta}=\beta P_{0} \eta_{0}\left(P_{\mathrm{m}}-P\right)(a+b \theta)$

with the constant differential equations, the explicit general solution of $P$ can be obtained by the following equation:

$\int \frac{\mathrm{d} P}{\mathrm{~d} \theta}=\beta P_{0} \eta_{0} \int\left(P_{\mathrm{m}}-P\right)(a+b \theta)$

$P=P_{\mathrm{m}}-\frac{1}{C \mathrm{e}^{\beta P_{0} \eta_{0}\left(a \theta+\frac{b}{2} \theta^{2}\right)}}$

where $C$ is an integral constant. Based on the abovementioned hypotheses, SAP application does not bring 
about change of $P$ for air-dried or oven-dried soil, so the initial condition occurs as:

$P=P_{0}, \quad \theta=0$.

Substitution of Eq. 2 then yields:

$P_{0}=P_{\mathrm{m}}-C^{-1}$

Let $P_{\mathrm{m}}-P_{0}=K$, then

$K=C^{-1}$.

With relation Eq. 3, the special solution of differential equation Eq. 1 can be obtained as:

$P=P_{\mathrm{m}}-K \mathrm{e}^{-\beta P_{0} \eta_{0}\left(a \theta+c \theta^{2}\right)}$

where $c$ is $b / 2$, and the other symbols are the same to the corresponding formers, respectively. Since the study is on the volume increase after SAP-treated soil has absorbed water, $P$ is an increasing function, that is, it satisfies $a \geq-$ $2 c \theta$.

Therefore, Eq. 5 is a numerical model for describing the volume change after SAP-treated soil has absorbed water.

Let $I=\{\theta \mid 0 \leq \theta \leq \xi\}$, where $\xi \in R_{+}$, and $R_{+}$is a positive real number, and $f(\theta, P)=\beta P_{0} \eta_{0}\left(P_{\mathrm{m}}-P\right)(a+b \theta)$, then $f$ and $\frac{\partial f}{\partial P}$ are both continuous functions when $\theta \in I$. Thus, Eq. 5 is the only solution to the differential equation derived from Eqs. 1 and 3 in terms of the initial conditions.

However, in mathematics, when $\theta \rightarrow \infty$, then $f \rightarrow \infty$ which shows that the solution to Eq. 1 has singular points $P_{\mathrm{S}}$.

The differential equation composed of Eq. 1 and initial condition 3 satisfies that $f$ and $\frac{\partial f}{\partial P}$ are both continuous functions, besides, the explicit solution to Eq. 2 has local boundary, so $P$ can be continued to $I_{\mathrm{m}}=\{\theta \mid 0 \leq \theta<\infty\}$.

In fact, with Eq. 2 and the relation $P_{\mathrm{s}}=P_{\mathrm{m}}$, the following equation can be obtained:

$\lim _{\theta \rightarrow \infty}\left\{P\left(\theta, \theta_{0}, P_{0}\right)-P_{\mathrm{s}}\right\}=0$.

Therefore, the special solution formula is asymptotically stable.

Based on the above-mentioned discussion, Eq. 1 has practical sense when describing the volume change of watered SAP-treated soil, that is, the volume of SAPtreated soil changes after it has absorbed water, and once the volume has reached a maximum value $P_{\mathrm{m}}$, it will stop changing no matter how much more water is added.

\section{Parameters}

To use this model, the parameters $\eta_{0}, a$ and $c$ need to be calculated using the experimental data.

According to Eq. 5, the following equation can be given:
$P_{\mathrm{m}}-P=\left(P_{\mathrm{m}}-P_{0}\right) \mathrm{e}^{-\beta P_{0} \eta_{0}\left(a \theta+c \theta^{2}\right)}$.

To solve this equation, take logarithms of both sides, then

$\ln \left(P_{\mathrm{m}}-P\right)=\ln \left(P_{\mathrm{m}}-P_{0}\right)-\beta P_{0} \eta_{0}\left(a \theta+c \theta^{2}\right)$

and hence,

$\ln \frac{\left(P_{\mathrm{m}}-P\right)}{\left(P_{\mathrm{m}}-P_{0}\right)} / \beta P_{0} \theta=-\eta_{0} c \theta-\eta_{0} a$

Equation 6 is a linear equation about water content $\theta$, wherein $\eta_{0} c$ is the slope of straight line and $\eta_{0} a$ is the intercept of straight line.

The parameters $\eta_{0}, a$ and $c$ in the model can be determined with $P$, which is measured in SAP-treated soil at different water contents with different SAP application rate. As can be seen from Eq. 6, the model actually has only two parameters, i.e., $\eta_{0} c$ and $\eta_{0} a$.

Four different SAP application rates were studied. The data, respectively, obtained in SAP: dry soil ratios of 1:5,000, 1:2,000 and 1:500 were used to determine the parameters. After the data were optimized and calculated, the result is as follows.

In terms of loam, $\eta_{0} c$ and $\eta_{0} a$ are calculated as:

$\left\{\begin{array}{l}\eta_{0} c=0.25 \times 10^{6} \\ \eta_{0} a=-0.39 \times 10^{5}\end{array}\right.$

so the model for loam is:

$\ln \frac{\left(P_{\mathrm{m}}-P\right)}{\left(P_{\mathrm{m}}-P_{0}\right)} / \beta P_{0} \theta=-\eta_{0} c \theta-\eta_{0} a$.

In this model, the relation between SAP application rate and $P_{\mathrm{m}}$ is shown in Fig. 3.

Thus, $P_{\mathrm{m}}$ can be obtained as:

$P_{\mathrm{m}}=-1,638 \times W^{2}+25.796 \times W+0.703$.

Due to $W=\beta P_{0}$, substitution of Eq. 7 is:

$\begin{aligned} & \ln \frac{\left(-1,638 \times W^{2}+25.796 \times W+0.703-P\right)}{\left(-1,638 \times W^{2}+25.796 \times W+0.703-P_{0}\right)} / W \theta \\ & \quad=-0.25 \times 10^{6} \theta+0.39 \times 10^{5}\end{aligned}$

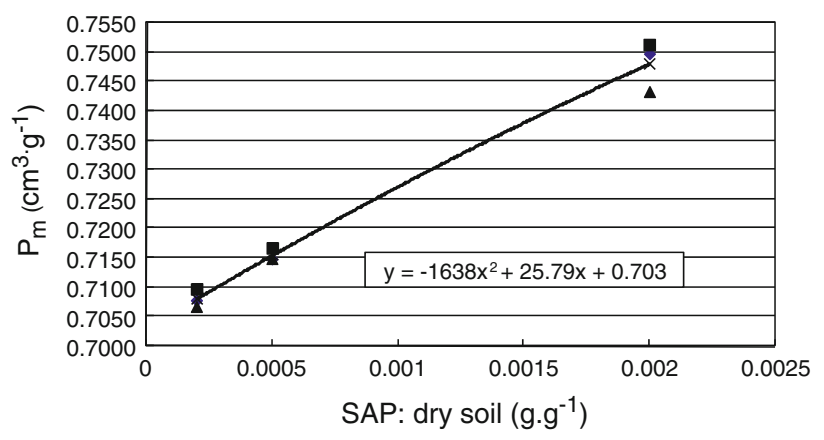

Fig. 3 Relation between SAP application rate and $P_{\mathrm{m}}$ for loam 
where $P_{0}=0.6452$, and the other symbols are the same to the corresponding formers, respectively.

In terms of loam, $\eta_{0} c$ and $\eta_{0} a$ are calculated as:

$\left\{\begin{array}{l}\eta_{0} c=0.81 \times 10^{5} \\ \eta_{0} a=-0.18 \times 10^{5}\end{array}\right.$

so the model for sandy loam is:

$\ln \frac{\left(P_{\mathrm{m}}-P\right)}{\left(P_{\mathrm{m}}-P_{0}\right)} / \beta P_{0} \theta=-\eta_{0} c \theta-\eta_{0} a$

In this model, the relation between SAP application rate and $P_{\mathrm{m}}$ is shown in Fig. 4.

Thus, $P_{\mathrm{m}}$ can be obtained as:

$P_{\mathrm{m}}=-18,680 \times W^{2}+71.877 \times W+0.679$.

Due to $W=\beta P_{0}$, substitution of Eq. 10 gives:

$$
\begin{aligned}
& \ln \frac{\left(-18,680 \times W^{2}+71.877 \times W+0.679-P\right)}{\left(-18,680 \times W^{2}+71.877 \times W+0.679-P_{0}\right)} / W \theta \\
& \quad=-0.81 \times 10^{5} \theta+0.18 \times 10^{5}
\end{aligned}
$$

where $P_{0}=0.6711$, and the other symbols are the same to the corresponding formers, respectively.

\section{Test model}

The model is tested with the data at SAP:dry soil ratio of 1:1,000. The results are shown in Figs. 5 and 6. They indicate that the average deviation of specific volume $P$ is approximately 0.01 . Thus, the model achieved satisfying simulation results.

Besides the above case, we also calculated the parameters of the model using the data of any three of these four ratios, respectively, and tested the model using the data of the rest one ratio, see Table 4 . It shows that the average deviation is $0.0099-0.016$ for the loam and 0.0094-0.013 for the sandy loam, so simulation results are satisfying, and the model is reliable.

The range of 1:5,000-1:500 of SAP:dry soil ratio has basically covered all the application circumstances for

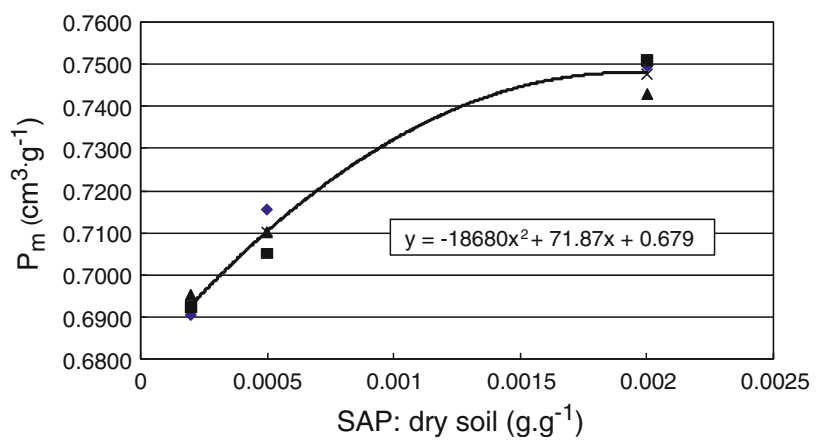

Fig. 4 Relation between SAP application rate and $P_{\mathrm{m}}$ for sandy loam

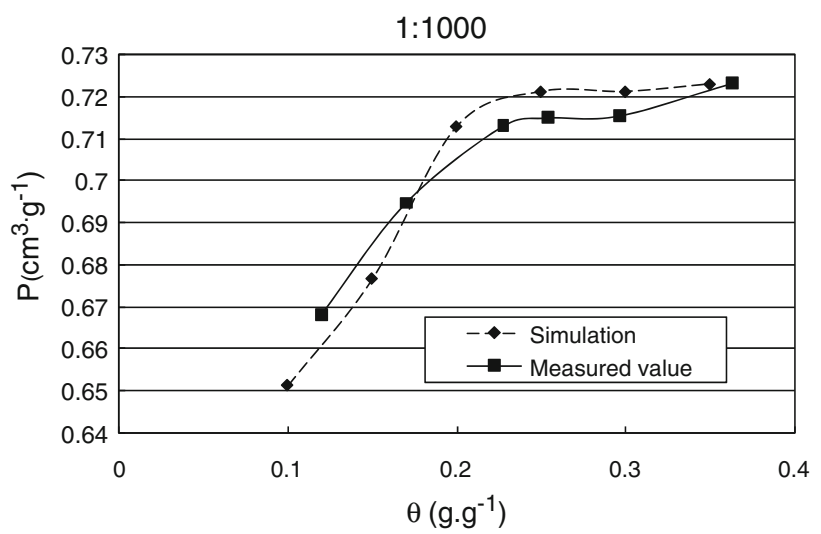

Fig. 5 Specific volume $P$ of SAP-treated loam versus water content $\theta$

$1: 1000$

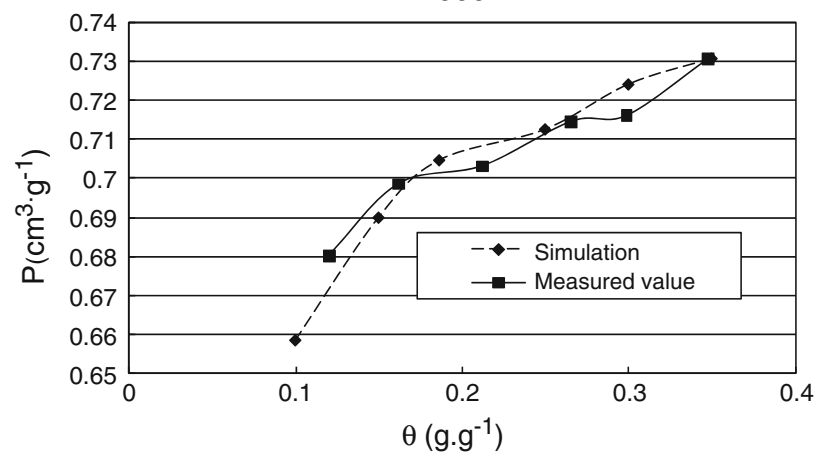

Fig. 6 Specific volume $P$ of SAP-treated sandy loam versus water content $\theta$

different agricultural crops. The model can be applied to the other ratios and other soil types which are not involved in the experiment. If the soil type and its parameters are, respectively, the same to those used in this paper, the model and its parameters calculated in this paper can be directly used. In other cases, the generic model will be used, but the parameters of the model need to be calculated with the specific experimental data. The following is the application of model (Eqs. 9, 12).

\section{Soil swelling ratio}

Based on Eqs. 9 and 12, porosity change of watered SAPtreated soil can be analyzed. By using the models, $P-\theta$ curve of each soil sample at different SAP application rates can be obtained, thereby, the model for volume change of watered SAP-treated soil can be constructed, which is the key to study soil swelling.

Soil swelling ratio Assume the specific volume of SAPtreated soil is $P_{i}(i=1,2, \ldots)$ at each of the different water 
Table 4 Average deviation of $P$ at different SAP:dry soil ratios

\begin{tabular}{lll}
\hline Test (SAP:dry soil ratio) & & $\begin{array}{c}\text { Average } \\
\text { deviation of } P\end{array}$ \\
\hline Loam $\left(P_{0}=0.6452\right)$ & $\ln \frac{\left(-2,941 \times W^{2}+33.649 \times W+0.6827-P\right)}{\left(-2,941 \times W^{2}+33.649 \times W+0.6827-P_{0}\right)} / W \theta=-0.29 \times 10^{6} \theta+0.42 \times 10^{5}$ & 0.016 \\
$1: 500$ & $\ln \frac{\left(-1,6851 \times W^{2}+84.991 \times W+0.6849-P\right)}{\left(-1,6851 \times W^{2}+84.991 \times W+0.6849-P_{0}\right)} / W \theta=-0.36 \times 10^{6} \theta+0.61 \times 10^{5}$ & 0.0099 \\
$1: 2,000$ & $\ln \frac{\left(-1,342 \times W^{2}+20.662 \times W+0.6795-P\right)}{\left(-1,342 \times W^{2}+20.662 \times W+0.6795-P_{0}\right)} / W \theta=-0.45 \times 10^{6} \theta+0.68 \times 10^{5}$ & 0.013 \\
$1: 5,000$ & $\ln \frac{\left(-35,984 \times W^{2}+91.568 \times W+0.6871-P\right)}{\left(-35,984 \times W^{2}+91.568 \times W+0.6871-P_{0}\right)} / W \theta=-0.75 \times 10^{5} \theta+0.14 \times 10^{5}$ & 0.013 \\
Sandy loam $\left(P_{0}=0.6711\right)$ & $\ln \frac{\left(-10,546 \times W^{2}+65.278 \times W+0.6913-P\right)}{\left(-10,546 \times W^{2}+65.478 \times W+0.6913-P_{0}\right)} / W \theta=-0.88 \times 10^{5} \theta+0.27 \times 10^{5}$ & 0.0094 \\
$1: 500$ & $\ln \frac{\left(-12,960 \times W^{2}+66.957 \times W+0.6821-P\right)}{\left(-12,960 \times W^{2}+66.957 \times W+0.6821-P_{0}\right)} / W \theta=-0.80 \times 10^{5} \theta+0.16 \times 10^{5}$ & 0.011 \\
$1: 2,000$ & & \\
$1: 5,000$ & &
\end{tabular}

contents, and $P_{0}$ is the specific volume of the corresponding air-dried soil or oven-dried soil, then swelling ratio can be measured by the relation:

$r=\frac{P_{i}}{P_{0}}=\frac{V_{i} / m}{V_{0} / m}=\frac{V_{i}}{V_{0}}$

where $V / m$ is the formula of $P$, and $V_{i} / V_{0}$ is the ratio of the volume of SAP-treated soil at different water contents to that of air-dried or oven-dried soil (see Figs. 7, 8).

As can be seen from Figs. 7 and 8, whether it is loam or sandy loam, the swelling ratio $r$ increases with water content $\theta$. As for the same soil sample, the higher SAP application rate, the higher $r$ is, namely, the higher water content, the more SAP absorbs water and the more the soil swells, and thereby the value of $r$ is higher.

According to the above-mentioned simulation process, the value of swelling ratio can be obtained after the parameters have been calculated. Since volume rate closely relates to volume ratio $r$, that is, volume rate increases with volume ratio, no more statement about volume rate is made herein.

Soil porosity and saturated water content

$\phi=1-\frac{\rho_{b}}{\rho_{s}}$

The formula of soil porosity is

$\phi=1-\frac{\rho_{b}}{\rho_{s}}$

where $\rho_{b}$ is the density of SAP-treated soil at different water contents; $\rho_{s}$ is the density of original soil; and $\Phi$ can also be regarded as the volumetric moisture content of SAP-treated soil at a certain water content (see Fig. 9).
Fig. 7 Swelling ratio $r$ of SAPtreated loam versus water content $\theta$ (SAP:soil $=1: 5,000$, $1: 2,000,1: 1,000,1: 500)$
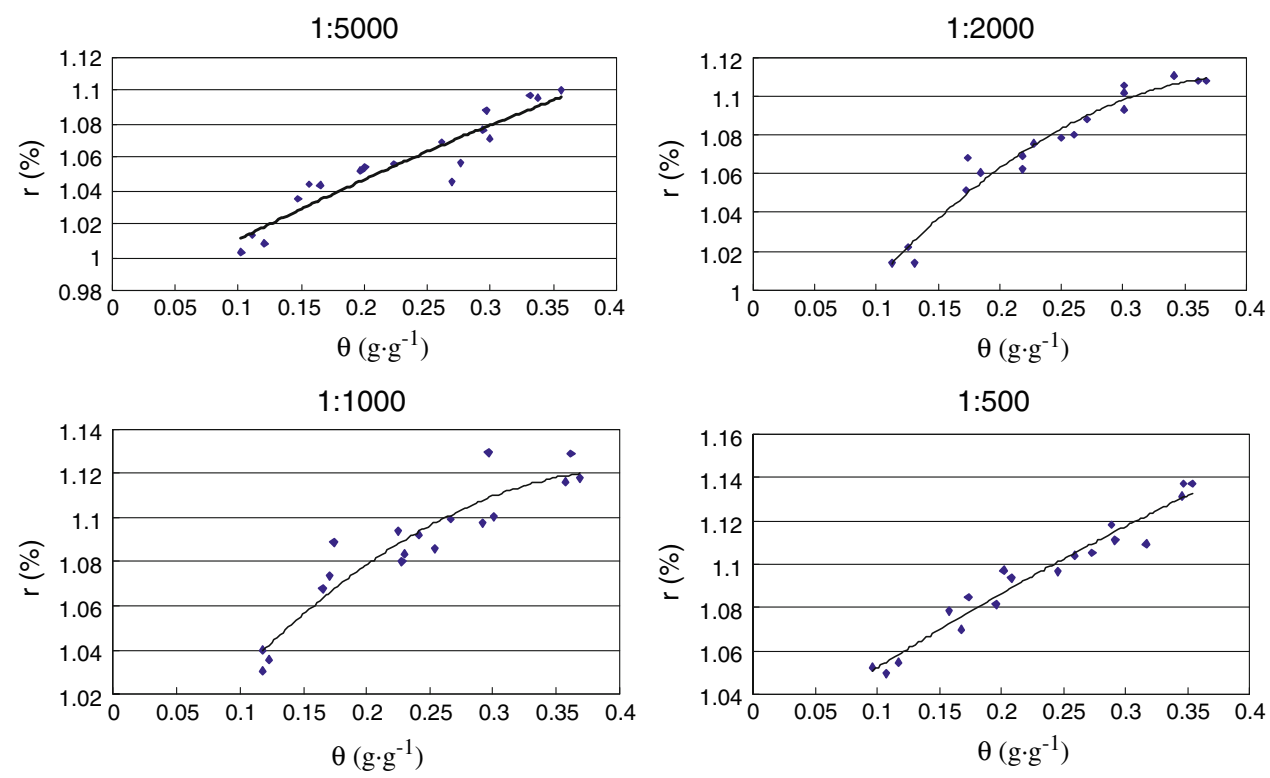
Fig. 8 Swelling ratio $r$ of SAPtreated sandy loam versus water content $\theta$ (SAP:soil $=1: 5,000$, $1: 2,000,1: 1,000,1: 500)$
Fig. 9 Porosity $\Phi$ of SAPtreated soil versus water content $\theta$ (SAP:soil $=1: 5,000,1: 2,000$, $1: 1,000,1: 500)$
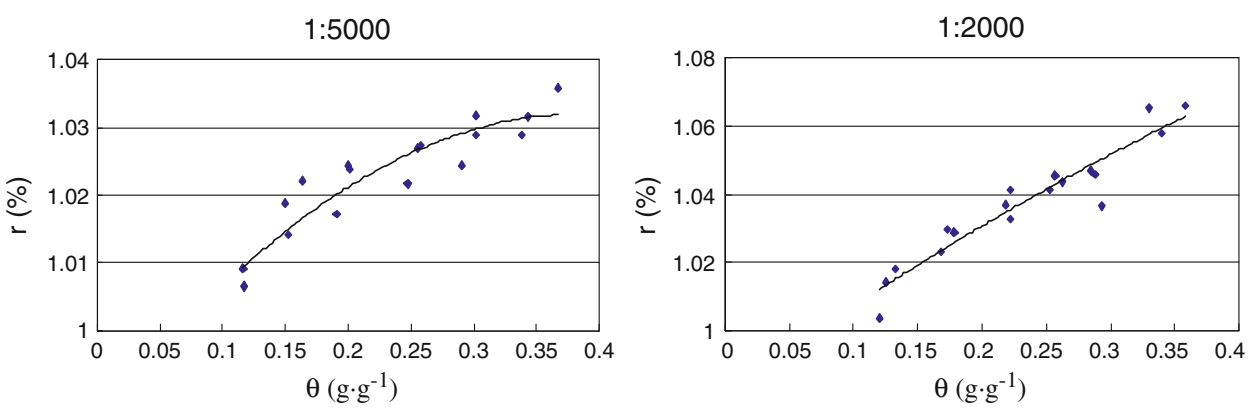

1:1000
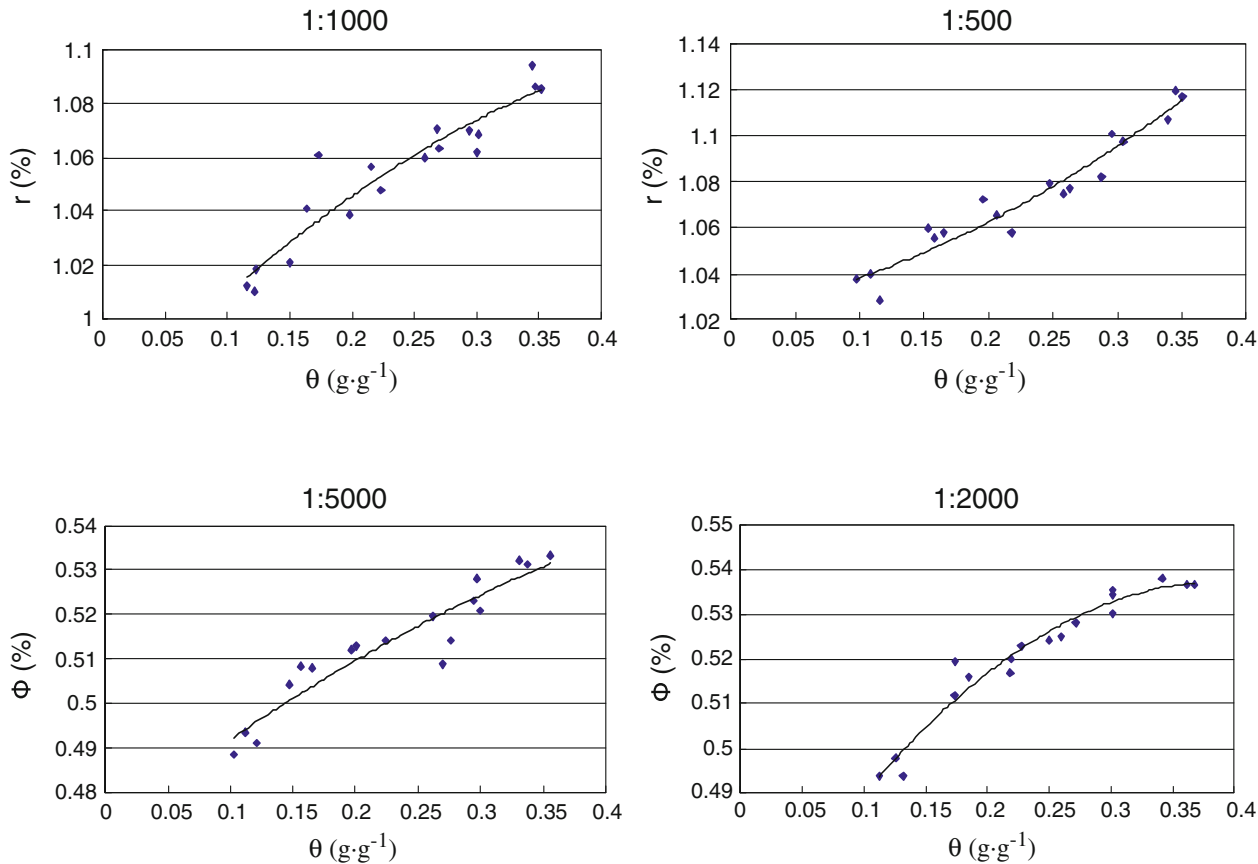

$1: 1000$
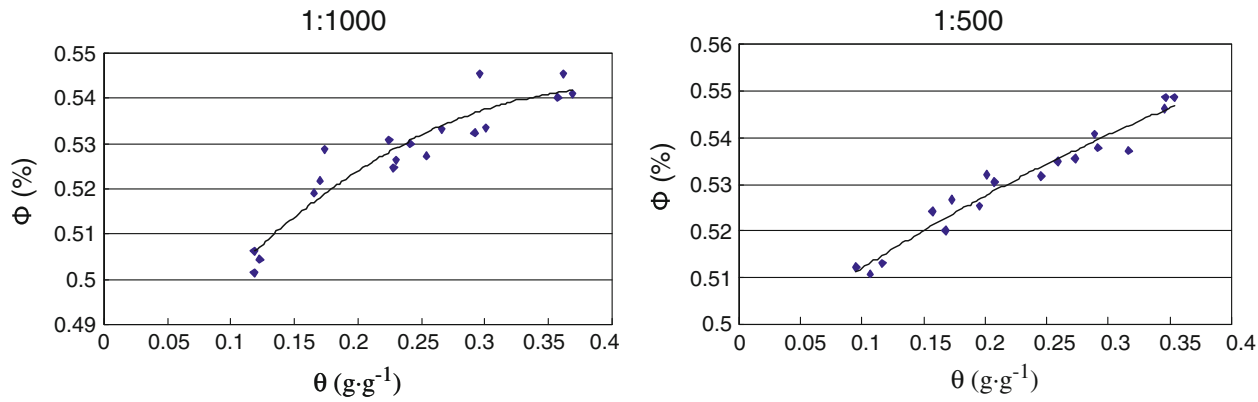

Figure 9 shows that, for loam, soil porosity $\Phi$ increases with water content $\theta$; for the same soil sample, the higher the SAP application rate, the higher soil porosity $\Phi$ is. Quantitative expression of porosity of SAP-treated soil has an important significance for the practical application of SAP and for water movement, solute transport and root water uptake of SAP-treated soil.

With this model, the porosity of SAP-treated soil at any water content can be determined. In addition, by using this model, $\Phi$ can be determined and then used to calculate transfer functions so as to provide a basis for determining hydraulic conductivity of SAP-treated soil.

\section{Discussion}

After the soil was treated with SAP, the originally stable soil physical properties are changed, so SAP-treated soil is assumed as a kind of soil with super capacity of absorbing and desorbing water. Only by this, can the methods and formulas adaptive to general physical parameters be used in this study.

Soil physical properties change constantly after it is treated with SAP, so the changes occurring in the course of measurement have to be ignored. As we all know, SAP's capacity of absorbing and desorbing water is a physical 
process. Although the model has been used to determine the parameters and tested, a lot more need to be further studied on the properties of SAP-treated soil, such as: to conduct an experiment to study its repeated drying-wetting alternation condition as a basis for further quantitative study; to construct a model in the field circumstances where SAP-treated soil coexists with original soil; to study the relation between soil physical properties and SAP's useful time; to study the fate of those changed porosity after SAP is invalidated; to study water movement, solute transport and root water uptake of SAP-treated soil; and to study the effect of SAP on crop transpiration, etc.

\section{Conclusion}

The study shows that the application of SAP can reduce soil bulk density, improve soil permeability and cause soil swelling. In addition, the paper constructed a model for porosity change in SAP-treated soil after it had absorbed water, which is $\ln \frac{\left(P_{\mathrm{m}}-P\right)}{\left(P_{\mathrm{m}}-P_{0}\right)} / \beta P_{0} \theta=-\eta_{0} c \theta-\eta_{0} a$. This is a generic model. Two soil samples, i.e., loam and sandy loam, were used to calculate parameters and tested the model, and the result showed the model is reliable.

\section{References}

Achwal WB (1997) Optimum conditions for microbial degradation of poly (vinyl alcohol) in wastewater. Colourage 44:47-48

David C, De KC (1994) The biodegradation of polymers: recent results. Angew Makromol Chem 216:21-35

Fanta GF, Burr RC, Doane WM et al (1971) Influence of starchgranule swelling on graft-copolymer composition-comparison of monomers. J Appl Polym Sci 15:2651-2660

Gugliemelli LA, Doane WM, Russell CR (1979) Preparation of soapless latexes by sonification of starch-based poly(isoprene-coacrylonitrile) graft reaction mixtures. J Appl Polym Sci 23:635644
Han YG, Yang PL, Xu L (2005) Experimental studies on increase of yield and soil moisture of fruit tree by using super absorbent polymers. Sci Agric Sin 38:2486-2491

Hemyari P, Nofiiger DL (1981) Super slurper effects on crust strength water retention, and water infiltration of soils. Soil Sci Soc Am J 45:799-801

Janardan SJ (1998) Effect of stockosorb polymers and potassium levels on potato and onion. J Potassium Res 4:78-82

Li DJ, Yang PL, Han YG (2004) Application effects of super absorbent polymers on grape cultivation. In: Huang GH, Luis SP (eds) Land and water management decision tools and practices. China Agricultural Science and Technology Publishing House, Beijing, pp 798-803

Liu IS, Rempel GL (1997) Effects of organic solvents on the synthesis of super absorbents. J Appl Polym Sci 64:1345-1351

Liu RF, Zong L, Zhang CW (2005) Effect of multifunctional composite on soil physical properties. Chin Agric Sci Bull $21: 424-426$

Matsubara Sangyo Co Ltd, Toa Gosei Chemical Industry Co Ltd (2008) Water-absorbent resins and photochemical method for their manufacture. Jpn Kokai Tokkyo Koho:JP0892307

Nimah MN, Ryan J, Chaudhry MA (1983) Effect of synthetic conditioners on soil-water retention, hydraulic conductivity, porosity, and aggregation. Soil Sci Soc Am J 47:742-745

Swietlik D (1989) Effect of soil amendment with viterra hydrogel on establishment of newly planted grapefruit trees cv ruby red. Commun Soil Sci Plant Anal 20:1697-1705

Wang GJ, Li M, Chen XF (1998) Preparation and water-absorbent properties of a water-swellable rubber. J Appl Polym Sci 68:1219-1224

Wang WZ, Rong JC, She WN (2000a) The characteristics and application of the filling ointment of water-absorbent expansive water blocking cable. J Electr Insul Mater 3:22-24

Wang BR, He KN, Shi CQ (2000b) The application of super absorbent polymers in the forestation and virescence. J Soil Water Conserv 4:22-24

Woodhouse J, Johnson MS (1991) Effect of super absorbent polymers on survival and growth of crop seedling. Agric Water Manag 20:63-70

Yang PL, Wang CZ, Ren SM (2003) Experimental studies of affections on the absorbable and holding characteristics of water retaining agent in different solution environments and the approaches to increasing its field efficiency. Water-Saving Agriculture and Sustainable Use of Water and Land Resources, pp 104-109 